\title{
First Diagonal Cracking and Ultimate Shear of I-Shaped Reinforced Girders of Ultra High Performance Fiber Reinforced Concrete without Stirrup
}

\author{
Xiangguo $\mathrm{Wu}^{1)}$ and Sang-Mook $\mathrm{Han}^{2)}$
}

\author{
(Received January 28, 2008, Revised September 30, 2008, Accepted September 30, 2008)
}

\begin{abstract}
The first diagonal cracking and ultimate shear load of reinforced girder made of ultra high performance fiber reinforced concrete (UHPFRC) were investigated in this paper. Eleven girders were tested in which eight girders failed in shear. A simplified formulation for the first diagonal cracking load was proposed. An analytical model to predict the ultimate shear load was formulated based on the two bounds theory. A fiber reinforcing parameter was constituted based on the random assumption of steel fiber uniform distribution. The predicted values were compared with the conventional predictions and the test results. The proposed equation can be used for the first cracking status analysis, while the proposed equations for computing the ultimate shear strength can be used for the ultimate failure status analysis, which can also be utilized for numerical limit analysis of reinforced UHPFRC girder. The established fiber reinforcing theoretical model can also be a reference for micro-mechanics analysis of UHPFRC.
\end{abstract}

Keywords: two bounds theory, ultra-high performance, steel fiber, reinforced bar; girder, cracking load, ultimate shear.

\section{Introduction}

Ultra high performance fiber reinforced concretes (UHPFRC), a new type of fiber reinforced concrete (FRC), has high durability, compressive strength over $140 \mathrm{MPa}$, flexural strength of about $40 \mathrm{MPa}$, and tensile strength in the range of $8 \sim 12 \mathrm{MPa}$. UHPFRC has been used in practice for several bridges recently, such as the Shepherds Bridge in Australia, ${ }^{1}$ the Wapello Bridge in Iowa-U.S. and the Kuyshu Expressway Bridge in Japan. ${ }^{2}$ An important work was also performed in the U.S. by FHWA $^{3}$ in order to design short span bridge of UHPFRC. The properties of UHPFRC structure are still in progress worldwide now.

UHPFRC shows quasi-brittle characteristic under tension, obvious ductile deformation and multiple cracking behaviors under compression and bending. Ductile deformation occurs in the compressive zone of UHPFRC reinforced girder without stirrups. There exists a certain gap between the first diagonal cracking load (FDCL) and ultimate shear failure load (USFL) of UHPFRC reinforced girder. Since ductile and multiple cracking performance of UHPFRC, two limit status are defined here, i.e. the first cracking status and the ultimate failure status, for UHPFRC reinforced girder to satisfy a different analysis degree

\footnotetext{
${ }^{1)}$ School of Architecture Engineering, Harbin Engineering University, Harbin, 150001 China.

${ }^{2)}$ KCI Member, School of Civil Engineering, Kumoh National Institute of Technology, Gumi 730-701 Korea. E-mail: smhan@ kumoh.ac.kr

Copyright (c) 2009, Korea Concrete Institute. All rights reserved, including the making of copies without the written permission of the copyright proprietors.
}

requirement. Luca Sorelli et al. carried out the work focusing on the analysis and the risk assessment of early age cracking for structures made of UHPFRC. ${ }^{4}$ The early age cracking is mainly induced by the highly exothermic reaction. Conventional formulae of USFL which are based on normal FRC and high strength concrete beams are not appropriate for UHPFRC reinforced girder. To the best knowledge of the authors, there have no formula to predict FDCL of UHPFRC reinforced girder by now. An accurate USFL prediction is important for the ultimate failure status analysis of UHPFRC reinforced girder.

Plasticity limit theory mainly includes the lower-bound theorem, the upper-bound theorem, and the uniqueness theorem. ${ }^{5}$ Each one was employed here to constitute USFL. The plasticity theory has been used to predict upper-bound solutions for continuous deep beams. ${ }^{6}$ To apply the lower-bound theorem in UHPFRC reinforced girder, loading transferring path which is simplified as a straight diagonal yielding line along the web and flanges. The lower bound i.e. the cracking strength can be derived from the equilibriums at the diagonal failure section.

Ductile compression and multiple cracking attribute to the reinforcing influences of steel fibers. The fiber reinforcing parameter expressed by the term $V_{f} L_{f} / D_{f}$ is lack of exact micromechanics meanings. Here $V_{f}, L_{f}$, and $D_{f}$ are fiber volume fraction, fiber length and fiber diameter, respectively. However, physical parameters beside geometrical parameters also affect the reinforcing mechanism. More precise simulation of fiber contribution to USFL was constituted here considering fiber reinforcing parameters such as volume fraction, fiber length, diameter, interfacial bonding strength and tensile strength. Both fiber orientation and fiber pulling-out length distributions were assumed as uniform distribution. The theoretical model of fiber 
reinforcing was applied to derive the upper bound solution of UHPFRC reinforced girder.

Based on the kinematical admissible failure mechanism, energy principle was used to compute the upper bound in which virtual work was divided into two parts induced by matrix and steel fibers. According to the uniqueness theorem, the lowest upper bound solution and the highest lower-bound solution i.e. the interaction of the two bounds constitute USFL of UHPFRC reinforced girder. Iterative method was applied during the calculations.

Experimental tests of UHPFRC reinforced girder with three types of tendons and shear span ratio were carried out. To obtain shear failure during the test, the girder with shear span ratio 8 was also designed with thin web. The theoretical analysis and proposed formula have good convergence with the test results. The FDCL formula proposed here can be the first cracking status analysis reference for UHPFRC reinforced girder. USFL model based on two bounds theory can be the ultimate failure status analysis reference for UHPFRC reinforced girder. The established fiber reinforcing model can also be a reference for micro-mechanics analysis of normal FRC.

\section{Material characteristics of UHPFRC}

The quality of the cementitious composites depends on constitution of materials, mixing method, and heat treatment after remolding. Exclusion of coarse aggregates enhances the homogeneity of matrix, and a good particle size distribution reduces porosity. The inclusion of steel fiber improves ductility and prevents the development of micro crack.

Steam curing at $90^{\circ} \mathrm{C}$ for 2 or 3 days after demolding, promotes hydration of binders and improves the density of composite matrix. It indicates the distinctive material properties of SFRCC in terms of both strength and durability.

\subsection{Composition of UHPFRC}

Ordinary portland cement (OPC) and silica fume (SF) are used in the experiment. Their physical and chemical properties are shown in Table 1. Domestic sand with grain size of $0.5 \mathrm{~mm}$ and below was used for fine aggregate, and coarse aggregate was not used. Two types of fine aggregate used are A with properties of density $2.62 \mathrm{~g} / \mathrm{cm}^{3}$, average grain size $0.3 \sim 0.5 \mathrm{~mm}$, $\mathrm{SiO}_{2} 93 \%$ and B with properties of density $2.62 \mathrm{~g} / \mathrm{cm}^{3}$, average grain size: $0.17 \sim 0.3 \mathrm{~mm}, \mathrm{SiO}_{2} 93 \%$. Polycarboxylic ether-type super plasticizers with density of $1.01 \mathrm{~g} / \mathrm{cm}^{3}$ and $30 \%$ of solid ingredient in dark brown liquid were used. Domestically processed filling powders with average grain size of $100 \mu \mathrm{m}$, $10 \mu \mathrm{m}, 5 \mu \mathrm{m}$, and $1 \mu \mathrm{m}$ were used. Filling powders with grain size of $100 \mu \mathrm{m}$ and $10 \mu \mathrm{m}$ were silica flour and those of $5 \mu \mathrm{m}$ and $1 \mu \mathrm{m}$ were lime stone powders, and their physical and chemical properties are shown in Table 2. Steel fiber with properties of density $7.5 \mathrm{~g} / \mathrm{cm}^{2}$, length $13 \mathrm{~mm}$, diameter $0.2 \mathrm{~mm}$ and tensile strength $2,500 \mathrm{MPa}$ is used to increase toughness at $2 \%$ concrete volume fraction. Table 3 below shows relative mix proportions of materials used in this experiment.

\subsection{Steam curing}

Steam curing conditions include relative humidity $95 \%$ and the temperature of $90 \pm 2{ }^{\circ} \mathrm{C}$ for 48 hours to activate the reactivity of UHPFRC.

\subsection{Mixing method}

UHPFRC is mixed using forced mixing type mixer with volume of $50 \mathrm{l}$ based on the sequence, time and speed listed in Fig. 1.

\section{Strength tests of I-girder and proposed FDCL}

\subsection{Specimens}

The main variables studied in the experimental programme were fiber volume fraction, reinforcing steel ratio, section type, and shear span ratio. Test specimens with fiber volume fraction of $1 \%, 2 \%$ and $3 \%$ were prepared to investigate the influence of the fiber quantity. In this case the other variables, reinforcing steel ratio and the length of the girder, were fixed. Similarly, variable steel ratios of $0.2,0.35,0.41$ and 0.5 were tested while the steel fiber volume ratio and the length of specimens were

Table 1 Physical and chemical properties of cement and mineral admixture.

\begin{tabular}{c|c|c|c|c|c|c}
\hline & Item & $\begin{array}{c}\text { Surface area } \\
\left(\mathrm{cm}^{2} / \mathrm{g}\right)\end{array}$ & $\begin{array}{c}\text { Density } \\
\left(\mathrm{g} / \mathrm{cm}^{3}\right)\end{array}$ & Ig.loss (\%) & \multicolumn{3}{|c}{ Chemical composition (\%) } \\
\cline { 5 - 7 } & 3,333 & 3.14 & 1.40 & $\mathrm{MgO}$ & $\mathrm{SO}_{3}$ & $\mathrm{SiO}_{2}$ \\
\hline \hline OPC & 200,000 & 2.10 & 1.50 & 0.1 & 2.3 & - \\
\hline $\mathrm{SF}$ & & 3.8 & - & 96.0 \\
\hline
\end{tabular}

Table 2 Physical and chemical properties of filling powders.

\begin{tabular}{|c|c|c|c|c|c|c|c|c|}
\hline \multirow{2}{*}{\multicolumn{2}{|c|}{$\begin{array}{ll}\text { Type } & \text { Item } \\
\text { Type } & \end{array}$}} & \multirow{3}{*}{$\begin{array}{c}\begin{array}{c}\text { Size } \\
(\mu \mathrm{m})\end{array} \\
100\end{array}$} & \multirow{3}{*}{$\begin{array}{c}\text { Ig.loss }(\%) \\
0.01\end{array}$} & \multicolumn{5}{|c|}{ Chemical composition (\%) } \\
\hline & & & & \multirow{2}{*}{$\begin{array}{c}\mathrm{Al}_{2} \mathrm{O}_{3} \\
0.15\end{array}$} & \multirow{2}{*}{$\begin{array}{l}\mathrm{MgO} \\
0.003\end{array}$} & \multirow{2}{*}{$\begin{array}{l}\mathrm{CaO} \\
0.004\end{array}$} & \multirow{2}{*}{$\frac{\mathrm{Fe}_{2} \mathrm{O}_{3}}{0.01}$} & \multirow{2}{*}{$\begin{array}{l}\mathrm{SiO}_{2} \\
99.3\end{array}$} \\
\hline Silica & $\overline{\mathrm{A}}$ & & & & & & & \\
\hline flour & $\mathrm{B}$ & 10 & 0.01 & 0.15 & 0.004 & 0.03 & 0.01 & 99.3 \\
\hline \multirow{2}{*}{$\begin{array}{l}\text { Lime stone } \\
\text { powders }\end{array}$} & $\mathrm{C}$ & 5 & 40.7 & 0.09 & 1.80 & 53.6 & 0.15 & 0.8 \\
\hline & $\mathrm{D}$ & 1 & 41.3 & 0.08 & 1.79 & 52.5 & 0.16 & 0.7 \\
\hline
\end{tabular}

Table 3 Mix compositions of UHPFRC (by weight).

\begin{tabular}{|c|c|c|c|c|c|c|c|}
\hline \multirow{2}{*}{ Item } & \multirow{2}{*}{$\mathrm{W} / \mathrm{B}$} & \multicolumn{2}{|c|}{ Binder } & \multirow{2}{*}{ Fine aggregate } & \multirow{2}{*}{ Filling powder } & \multirow{2}{*}{ Super plasticizer } & \multirow{2}{*}{ Fiber $\left(V_{f}\right)$} \\
\hline & & OPC & $\mathrm{SF}$ & & & & \\
\hline "Optimum mix design & (0.2 & 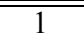 & 0.25 & "1.1 & 0.3 & 0.016 & 0.2 \\
\hline
\end{tabular}


Cement Silica

Fume Filling

Powder Sand
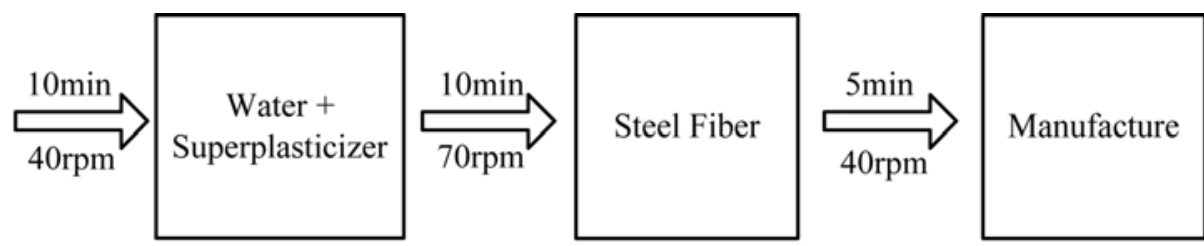

Fig. 1 Mixing method of UHPFRC.

held constant. Finally, to observe the behavior of the girders according to varying shear span ratio 4,6 , and 8 , the fiber quantity and reinforcing steel ratio were fixed. The dimensions of Ishaped girder are shown in Figs. 2 and 3. The specimens were designed to fail by either shear or flexure, depending on variables. Table 4 shows the details of test specimens. SR, VF and
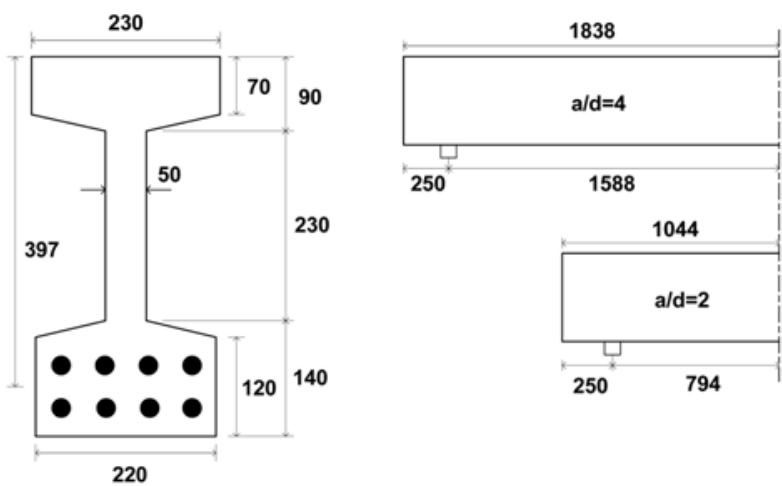

Fig. 2 Dimensions of A-type section.
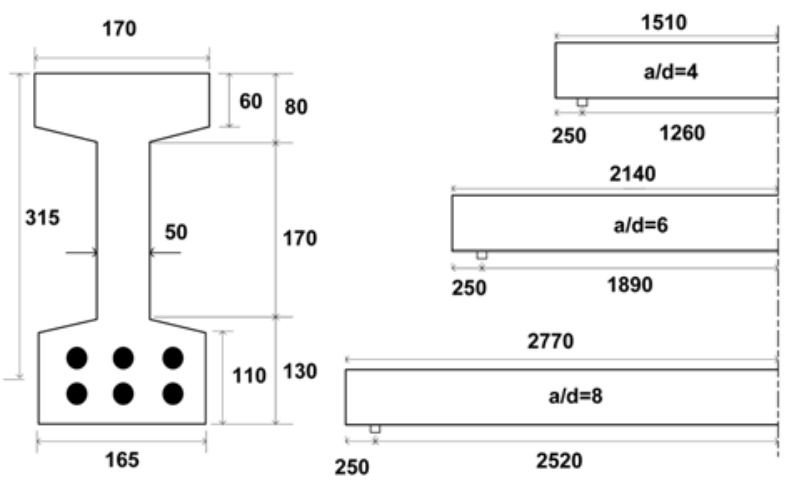

Fig. 3 Dimensions of B-type section.
SS means reinforcing steel ratio, fiber quantity and shear span ratio a/d respectively. The mixing proportion of UHPFRC with a compressive strength of $150 \mathrm{MPa}$, and composed materials, is shown in Table 3.

Three point load flexure tests were carried out with loading speed $1.0 \mathrm{~mm} / \mathrm{min}$ controlled by displacement. Load cell attached to the actuator measured loads. The first cracking load was determined by visual tracing of cracks on the specimens, and the ultimate limit loads were recorded during experiments.

\subsection{Strength test results}

\subsubsection{Effects of steel fiber}

The effects of steel fiber volume fraction on the behavior of the I-shaped section UHPFRC girder are shown in Fig. 4. The higher steel fiber volume fraction, the greater resisting force capacity of the girder can get. In addition, with increased steel fiber volume fraction, the level of displacement increases at the point of the maximum load. A higher steel fiber volume produces a steeper inclination in the load-displacement relationship

Table 4 Details of test specimens and failure mode.

\begin{tabular}{|c|c|c|c|c|c|c|c|c|}
\hline \multicolumn{2}{|c|}{ Types of specimen } & $\begin{array}{c}\text { Reinforcing } \\
\text { steel }\end{array}$ & $\begin{array}{c}\mathrm{a} / \mathrm{d} \\
\text { ratio }\end{array}$ & \begin{tabular}{|c|} 
Compressive \\
strength (MPa) \\
\end{tabular} & $\begin{array}{l}\text { Splitting tensile } \\
\text { strength (MPa) }\end{array}$ & $\begin{array}{c}\text { Flexural } \\
\text { strength (MPa) } \\
\end{array}$ & $\begin{array}{c}\text { Fiber quantity } \\
(\%)\end{array}$ & $\begin{array}{c}\text { Failure } \\
\text { mode }\end{array}$ \\
\hline \multirow{5}{*}{ A-type } & "SR20VF2SS4 & 4D-19 & 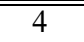 & 146 & 19 & 22 & 2 & Flexure \\
\hline & SR35VF2SS4 & $6 \mathrm{D}-22$ & 4 & 148 & 20 & 22 & 2 & Shear \\
\hline & SR50VF1SS4 & $8 \mathrm{D}-22$ & 4 & 144 & 14 & 16 & 1 & Shear \\
\hline & SR50VF2SS4 & $8 \mathrm{D}-22$ & 4 & 146 & 20 & 22 & 2 & Shear \\
\hline & SR50VF3SS4 & $8 \mathrm{D}-22$ & 4 & 152 & 25 & 26 & 3 & Shear \\
\hline \multirow{6}{*}{ B-type } & SR41VF2SS4 & 6D-19 & 4 & 146 & 20 & 22 & 2 & Flexure \\
\hline & SR41VF2SS6 & $6 \mathrm{D}-19$ & 6 & 147 & 20 & 22 & 2 & Shear \\
\hline & SR41VF2SS8 & $6 \mathrm{D}-19$ & 8 & 149 & 21 & 22 & 2 & Shear \\
\hline & SR50VF2SS4 & $4 \mathrm{D}-25$ & 4 & 146 & 20 & 22 & 2 & Shear \\
\hline & SR50VF2SS6 & $4 \mathrm{D}-25$ & 6 & 147 & 20 & 22 & 2 & Shear \\
\hline & SR50VF2SS8 & $4 \mathrm{D}-25$ & 8 & 146 & 19 & 22 & 2 & Flexure \\
\hline
\end{tabular}


in the softening region following the peak load. This phenomenon is caused by interlocking of the matrix and the fiber, and originates from the higher tensile resistance. The matrix strengths are similar. Hence the unloading beyond the peak load is larger for the material with higher fiber volume fraction.

\subsubsection{Effects of reinforcing steel}

Although the width of the web is very thin without stirrups, the failure mode of the girder with constant test variables (shear span ratio 4 and steel fiber volume fraction $4 \%$ ) is dependent on the reinforcing steel ratio (see Fig. 5). Flexural failure was observed in the test girder with a balanced steel ratio of 0.2 , while shear occurred in the girders with a balanced steel ration of 0.35 and 0.5 . Due to the thinness web and the absence of stirrups, shear resistance capacity is expected to be very low. However, this kind of girder can fail according to the flexural failure mode before shear failure because of the low reinforcing ratio. Beyond the peak load, resisting capacity is maintained at $85 \%$ of the maximum load until the vertical displacement of the center point reaches $100 \mathrm{~mm}$. This is a positive characteristic of UHPFRC as a structural member.

\subsubsection{Effects of shear span ratio}

Shear span ratio has a substantial effect on the failure behavior of the B-type section girder shown in Fig. 6. The load carrying capacity of the small shear span ratio girder is greater than that of large shear span ratio girder. The girder with a shear span ratio of 8 failed according to the flexural failure mode, despite balanced steel ratios of 0.41 and 0.5 .

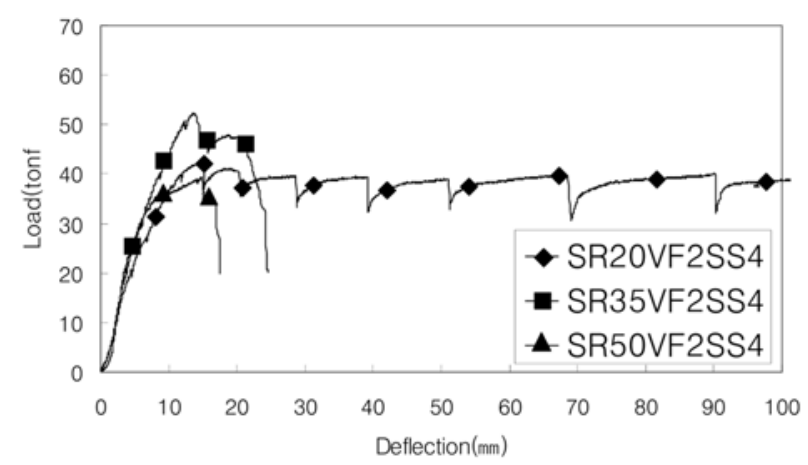

Fig. 5 Effect of reinforcing steel ratio.

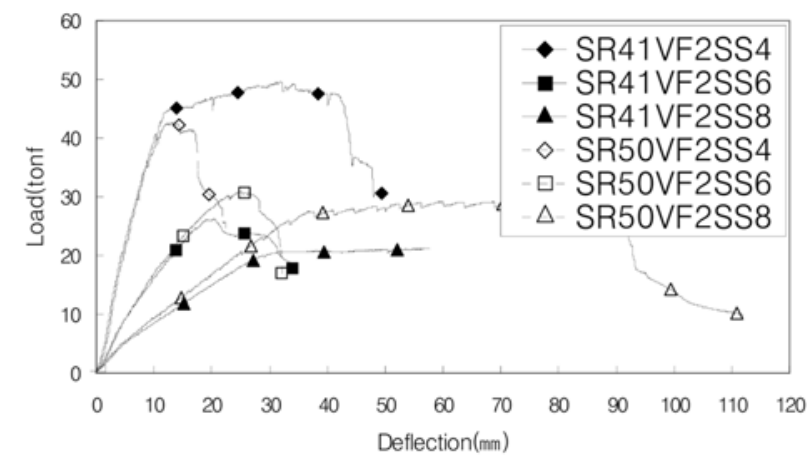

Fig. 6 Effect of shear span ratio.

\subsection{Proposed simple formula of FDCL for reinforced UHPFRC girder}

According to the test results analysis and traditional shear load formula from nowadays design code, the FDCL formula proposed here is related with the compressive strength, web width, effective height, shear span ratio, and fiber volume fraction of UHPFRC. Linear simple shape is originated from the traditional shear load design formula and the nonliear relations are obtained from the test results by regression analysis.

$$
V_{c}=\frac{\xi}{\sqrt{\lambda}(1+\lambda)}\left(\frac{b_{w}}{d}\right)^{0.5} f_{c k} b_{w} d
$$

in which, $\xi$ is the fiber volume fraction effective coefficient and $\xi=5.08 V_{f}^{0.2} \lambda$. is the shear span ratio and $\lambda=a / d$ in which a is the half shear span and $\mathrm{d}$ is the girder depth. $f_{c k}$ is the normal compressive strength of UHPFRC. $b_{w}$ is the girder web width. $V_{f}$ is the fiber volume fraction.

\section{Ultimate shear strength based on plastic limit analysis}

\subsection{Conventional formula of USFL for high strength concrete beam}

Shear strength and shear failure mechanism of fiber reinforced concrete have been extensively studied by researchers. For example, Mahmoud Imam et al. ${ }^{7}$ carried out numerous tests to investigate the shear behavior. Kwak et al. ${ }^{8}$ performed a USFL study of steel fiber reinforced concrete beams without stirrups, which included 12 fiber reinforced concrete beams. All the notations can be referenced in the references. Imam and Kwak proposed USFL prediction formula for normal and high strength FRC beam as shown in Eqs. (2) and (3). Both these formulae and comparisons are shown in Table 5 and Fig. 6.

$$
\begin{aligned}
& \text { Imam } v_{u}=0.54 \varphi \sqrt[3]{\rho}\left[\sqrt{f_{c k}}+249 \sqrt{\rho /(a / d)^{5}}\right] \\
& \text { Kwak } \quad v_{u}=A e f_{s p f c}{ }^{\exp 1}\left(\rho \frac{d}{a}\right)^{\exp 2}+B v_{b}^{\exp 3}
\end{aligned}
$$

\subsection{Ultimate limit load $V_{u}$ of UHPFRC I-girder (upper bound solution)}

Upper bound plasticity approach can be used to calculate the shear capacity. Hoang has previously modeled the shear strength of non-shear, longitudinally reinforced, and simply supported Tbeams under concentrated loading. ${ }^{9}$ Hoang's model for a Tbeam was modified to incorporate UHPFRC I-girder in this paper.

Ultimate limit load $V_{u}$ can be calculated according to the sliding failure mechanism along a virtual crack yielding line as shown in Fig. 7. Internal dissipation work is expressed by Eq. (4). It is noted that the ultimate shear strength can be divided into two components i.e. $V_{u c}$ and $V_{u f}$ as Eq. (5) resulted from matrix and fiber of UHPFRC.

$$
W=W_{c}+W_{f}
$$


Table 5 FDCL and USFL of test results and predictions.

\begin{tabular}{c|c|c|c|c|c|c|c|c}
\hline \multirow{2}{*}{ No. } & \multirow{2}{*}{ I-girder } & \multirow{2}{*}{$\begin{array}{c}f_{c k} \\
\mathrm{MPa}\end{array}$} & \multicolumn{2}{|c|}{ FDCL $(\mathrm{N})$} & \multicolumn{3}{|c}{ USFL (N) } \\
\cline { 5 - 9 } & & Prediction & $\begin{array}{c}\text { Test } \\
\text { results }\end{array}$ & $\begin{array}{c}\text { Imam } \\
\text { prediction }\end{array}$ & $\begin{array}{c}\text { Kwak } \\
\text { prediction }\end{array}$ & $\begin{array}{c}\text { Two bounds interaction } \\
\text { prediction }\end{array}$ & $\begin{array}{c}\text { Test } \\
\text { results }\end{array}$ \\
\hline \hline 1 & SR35VF2SS4 & 148 & 236,951 & 260,000 & 79,111 & 357,137 & 500,230 & 520,000 \\
\hline 2 & SR50VF1SS4 & 144 & 200,703 & 240,000 & 85,877 & 323,564 & 351,050 & 350,000 \\
\hline 3 & SR50VF2SS4 & 146 & 233,749 & 240,000 & 86,471 & 373,636 & 378,980 & 380,000 \\
\hline 4 & SR50VF3SS4 & 152 & 263,912 & 330,000 & 88,230 & 425,071 & 603,780 & 600,000 \\
\hline 5 & SR41VF2SS6 & 147 & 123,723 & 160,000 & 62,099 & 270,012 & 239,150 & 270,000 \\
\hline 6 & SR41VF2SS8 & 149 & 84,471 & 140,000 & 62,520 & 286,035 & 180,700 & 220,000 \\
\hline 7 & SR50VF2SS4 & 146 & 210,699 & 220,000 & 65,379 & 257,945 & 383,340 & 430,000 \\
\hline 8 & SR50VF2SS6 & 147 & 123,723 & 180,000 & 65,602 & 278,139 & 257,410 & 310,000 \\
\hline
\end{tabular}

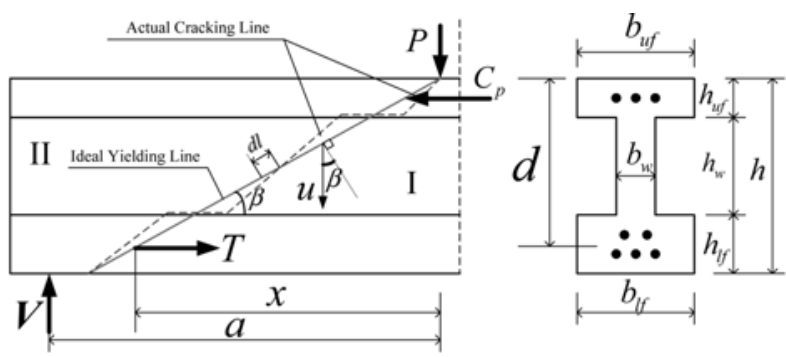

Fig. 7 UHPFRC l-girder model.

$$
V_{u}=V_{u c}+V_{u f}
$$

where, $W_{c}$ and $W_{f}$ are the work done by the matrix and fiber of UHPFRC during crack development. $V_{u c}$ is the upper solution of girder shear capacity component resulted by matrix virtual displacement.

\subsubsection{Shear capacity component of matrix $V_{u c}$}

According to geometry of the girder, the term of $W_{c}$ can be expressed as

$$
W_{c}=W_{c w}+W_{c u f}+W_{c l f}
$$

where, terms $W_{c w}, W_{c u f}$ and $W_{c l f}$ are the contributions from matrix web, matrix upper flange and matrix bottom flange. The mechanism consists of a sliding crack failure in web and two flanges and two diagonal cracks in the two flanges. The virtual work with virtual displacement can be written as

$$
V_{u c} \cdot u=W_{c}
$$

Based on the plane stress limit analysis of concrete plasticity, ${ }^{4}$ the dissipation work $W_{l}$ along the cracking surface can be simplified as

$$
W_{l}=0.5 f_{c}^{*} u b[1-\cos \beta] \quad \text { with } f_{t}^{*}=f_{c}^{*}
$$

in which, $\beta$ is the angle between ideal yielding line and neutral axis as shown in Fig. 1. $f_{t}^{*}$ and $f_{c}^{*}$ are the effective tensile strength and the effective compressive strength of UHPFRC respectively.

$$
\cos \beta=x / \sqrt{x^{2}+h^{2}}
$$

According to the concrete plasticity theory, ${ }^{5}$ the effective compressive strength $f_{c}^{*}$ with an effective factor $v$ is used with the relation of $f_{c}^{*}=v f_{c k}$ and $v=0.8 .^{10,11}$ In the case of a critical diagonal cracking, cracking surface is assumed to be fully developed. Thus a fully plastic equivalent stress distribution may be assumed, i.e. the tensile strength which is perpendicular to the cracking surface is distributed evenly with $f_{t}^{*}=\frac{1}{3} \gamma_{0} f_{t}$ and plasticity factor $\gamma_{0}$ about 1.7..$^{10,11}$

Based on Eq. (8), the virtual work along cracking surface can be expressed as

$$
W_{c w, c u f, c l f}=0.5 f_{c}^{*} u b_{w, u f, l f}(1-\cos \beta) h_{w, u f, l f} / \sin \beta
$$

where, $b_{w, u f, l f}$ and $h_{w, u f, l f}$ correspond to the disks width and height of web, upper flange and bottom flange, respectively.

In Fig. 7, the girder can be divided into two parts in which part II is assumed as a undeformed part, and the total virtual displacement of part I is noted as $u$, the total virtual work along the cracking line can be summarized as

$$
\begin{aligned}
W_{c} & =0.5 f_{c}^{*} \cdot u\left(\frac{1-\cos \beta}{\sin \beta}\right)\left(b_{w} h_{w}+b_{1} h_{1}+b_{2} h_{2}\right) \\
& =0.5 f_{c}^{*} \cdot u\left(\frac{1-\cos \beta}{\sin \beta}\right) A_{c}
\end{aligned}
$$

in which $A_{c}$ is the general cross section area of the girder. From Eqs. (7) and (11), the shear capacity component $V_{u c}$ can be obtained.

$$
V_{u c}=0.5 \gamma f_{c}^{*}\left(\frac{1-\cos \beta}{\sin \beta}\right) A_{c}
$$

where, $\gamma$ is model and safe factor and equals to 0.8 here.

\subsubsection{Shear loading capacity component of fiber $V_{u f}$}

There are several possible failure modes of UHPFRC such as fiber failure in tension, fiber pull-out and badly flawed fibers. Fiber pull-out was considered here since the fibers length $L_{f}$ is shorter than the fiber failure critical length $\mathrm{L}_{\mathrm{c}}=0.5 \sigma_{f} D_{f} / \tau_{f m}{ }^{13}$ in which $\sigma_{f}$ is the tensile strength of steel fiber, $\tau_{f m}$ is the interfacial bonding strength and $D_{f}$ is steel fiber diameter, respectively. Both fiber pull-out and fiber debonding are considered as energy dissipating processes. Pull-out work is defined as against sliding friction in extracting fibers from a broken matrix, and debonding 
is defined as destroying the interfacial bonding between fiber and the matrix.

Fibers are assumed to be uniformly distributed. On any section, fibers will distribute with equal probability either in its orientation or its pull-out length. Now, one micro-section on the crack cross section is considered. The micro section area with projection $b_{i} \times L_{f}$ as shown in Fig. 8 (a) is $d S=b_{i} \cdot l_{f}$ in which $b_{i}$ is disk width and $L_{f v i}$ is the vertical projection of steel fiber on cracking surface and $l_{j}$ is fiber embedded length. Parameter $N_{d s}$ is the total number of the steel fibers on one of the unit cube surfaces as shown in Fig. 8 (b). Here $L_{f}$ is steel fiber length.

Unit section $d S$ is amplified as Fig. 8 (b). It is easy to see stochastic orientation and stochastic pull-out length of fibers such as fiber $i$ with vertical projection length $L_{f v i}$. According to the stochastic assumption, fiber vertical projection is a random variable which belongs to uniform distribution in one closed interval. Now, all the fibers are aligned from 0 to $L_{f} / 2$ according to the vertical projection lengths $L_{f v i}$, and constitute one uniform difference sequence of $L_{f v i}$ as shown in Fig. 9 (a). The vertical projection length of $i$ can be expressed as

$$
L_{f v i}=\frac{L_{f}}{2 N_{d s}}(i-1)
$$

Corresponding to sequence $L_{f v i}$, sequence $l_{j}$ can be obtained as the fiber embedded length in the unit.

$$
l_{j}=\frac{1}{N_{d s}-1}\left(L_{f}-\frac{L_{f}}{2}\right) \cdot\left(N_{d s}-j\right)+\frac{L_{f}}{2}=\frac{L_{f}}{2}\left(1+\frac{N_{d s}-j}{N_{d s}-1}\right)
$$

$P_{i}$ and $P_{j}$, the occurrence probability of $L_{f v i}$ and $l_{j}$, equals to $\frac{1}{N_{d s}}$ with $L_{f v i} \in\left[0, L_{f} / 2\right]$ and $l_{j} \in\left[L_{f}, L_{f} / 2\right]$ for $i, j=1,2, L, N_{d s}$. Fiber volume fraction is defined as the fiber volume at the unit volume of UHPFRC. Here, the total number of the fibers in the unit should be considered with six surfaces of the unit and symmetrical fiber embedded on every surface. Therefore, coefficient 6 should be induced here.

$$
V_{f}=\frac{12}{L_{f}^{3}}\left(\frac{\pi D_{f}^{2}}{4}\right) \sum_{j=1}^{N_{d s}} l_{j}=\frac{9}{4} \pi N_{d s} \phi^{2}
$$

in which, $\phi=\frac{D_{f}}{L_{f}}$ is the slenderness of the fiber. The term $\sum_{j=1}^{N_{d s}} l_{j}$ can be obtained from Eq. (14) as $\frac{3}{4} N_{d s} L_{f}$. Hence parameter $N_{d s}$ can be obtained as

$$
N_{d s}=\frac{4 V_{f}}{9 \pi \phi^{2}}
$$

where, $V_{f}$ is the fiber volume fraction. Pull-out virtual work can be obtained by the interfacial shear strength multiplied by the pull-out area and be expressed as

$$
w_{f p i}=\frac{1}{2} \pi D_{f} \tau_{f m} L_{f v i}^{2} d_{f}
$$

where, bonding factor $d_{f}$ equals to $0.50,0.90$ and 1.00 for smooth, deformed and hooked fiber, respectively. By substituting Eqs. (13) into (17) and accumulating all the fibers on the micro section, integral virtual work of the fibers on micro section during pull-out can be written as

$$
d W_{f p}=\sum_{i=1}^{N_{d s}} w_{f p i}=\frac{\pi D_{f} d_{f} \tau_{f m} L_{f}^{2}}{48}\left(2 N_{d s}-3+\frac{1}{N_{d s}}\right)
$$

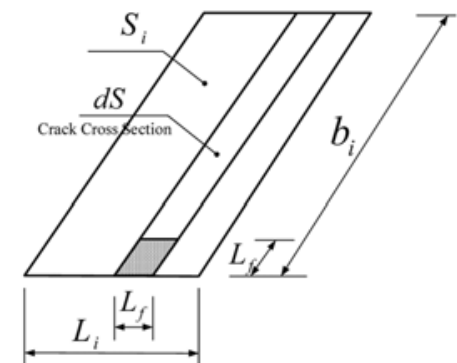

(a) Micro section

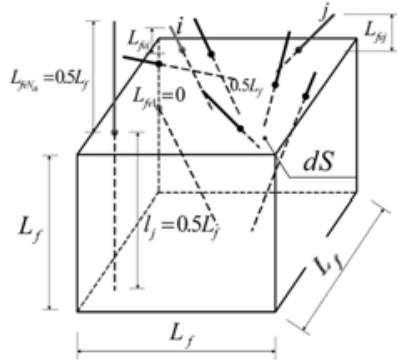

(b) Random distribution of fiber

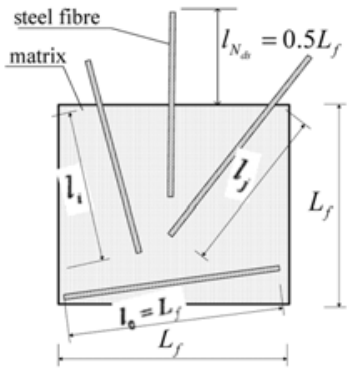

(c) Fiber projection

Fig. 8 Arbitrary distribution of fibers on the unit section.

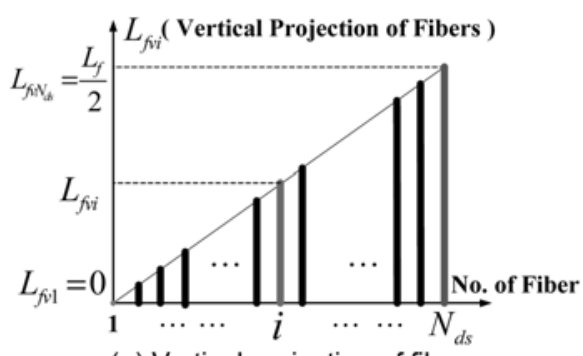

(a) Vertical projection of fibers

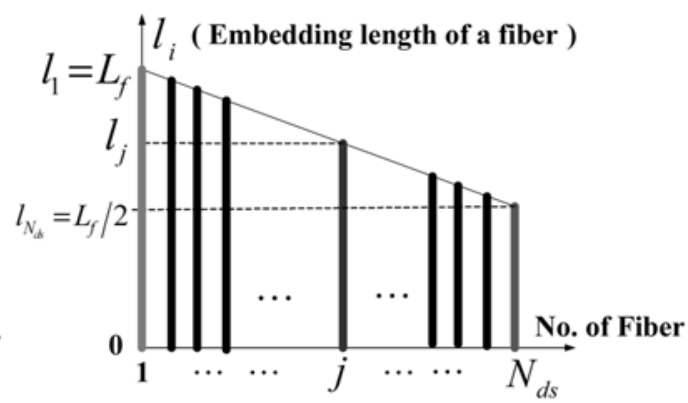

(b) Embedding length of fibers

Fig. 9 Vertical projection and embedding length of fibers. 
The term $-3+1 / N_{d s}$ can be omitted compared with $2 N_{d s}$. Therefore $d W_{f p}$ can be simplified as

$$
d W_{f p}=\frac{\pi}{24} b_{i} D_{f} d_{f} \tau_{f m} L_{f} N_{d s}
$$

By substituting Eq. (16) into Eq. (18), fiber pull-out work can be obtained.

$$
d W_{f p}=\frac{d_{f} \tau_{f m} V_{f} b_{i} L_{f}^{3}}{54 D_{f}}
$$

In a brittle matrix, debonding occurs ahead of the pull-out process. The debonded work is expressed as ${ }^{12}$

$$
w_{f d i}=\frac{\pi D_{f}^{2}}{48} \frac{\sigma_{f}}{E} \sigma_{f} L_{f v i} d_{f}
$$

where, $E$ is the modulus of the steel fiber. By substituting Eq. (13) into Eq. (20) and accumulating all the fibers on the micro section, debonded work of the fibers on micro a section during pull-out can be written as

$$
d W_{f d}=\sum_{i=1}^{N_{d s}} w_{f d i}=\frac{\pi D_{f}^{2}}{48} \frac{\sigma_{f}^{2}}{E} d \frac{L_{f}\left(N_{d s}-1\right)}{2}
$$

For large $N_{d s}, d W_{f d}$ can be written as

$$
d W_{f d}=\frac{\pi D_{f}^{2} \sigma_{f}^{2}}{96 E} d_{f} b_{i} N_{d s}
$$

By substituting Eq. (16) into Eq. (22), debonded work of the fiber can be written as

$$
d W_{f d}=\frac{d_{f} V_{f} b_{i} \sigma_{f}^{2} L_{f}^{2}}{216 E}
$$

Hence

$$
d W_{f}=d\left(W_{f p}+W_{f d}\right)=d W_{f p}+d W_{f d}
$$

By substituting Eqs. (19) and (23) into Eq. (24), integral virtual work of the fibers on the micro-section can be written as

$$
d W_{f}=\frac{b_{i} V_{f} d_{f} L_{f}^{2}}{54}\left(\frac{\tau_{f m} L_{f}}{D_{f}}+\frac{\sigma_{f}^{2}}{4 E}\right)
$$

The integral virtual work of fibers on crack section can be obtained as

$$
\begin{array}{r}
W_{f}=\sum_{w, u f, l f} \int_{S_{i}} d W_{f}=\frac{V_{f} d_{f} L_{f}}{54}\left(\frac{\tau_{f m} L_{f}}{D_{f}}+\frac{\sigma_{f}^{2}}{4 E}\right) . \\
\sum_{w, u f, l f} b_{i} L_{i}=\frac{V_{f} d_{f} L_{f} A_{c}}{54 \sin \beta}\left(\frac{\tau_{f m} L_{f}}{D_{f}}+\frac{\sigma_{f}^{2}}{4 E}\right)
\end{array}
$$

Pull-out interfacial displacement can be written as

$$
\begin{gathered}
\mu_{L p_{i}}=\sum_{i=1}^{N_{d s}}\left(L_{f v i} P_{i}\right)=\frac{L_{f}\left(N_{d s}-1\right)}{4 N_{d s}} \\
d u_{d S p}=N_{d s} u_{L_{i}}=\frac{1}{4} L_{f}\left(N_{d s}-1\right)
\end{gathered}
$$

Full debonding displacement is

$$
\begin{aligned}
& \mu_{L d_{i}}=\sum_{i=1}^{N_{d s}}\left(2 \frac{\sigma_{f}}{E} L_{f v i} P_{i}\right)=\frac{\sigma_{f} L_{f}\left(N_{d s}-1\right)}{2 E N_{d s}} \\
& d u_{d S d}=N_{d s} \mu_{L d_{i}}=\frac{\sigma_{f} L_{f}\left(N_{d s}-1\right)}{2 E}
\end{aligned}
$$

In this example, $d u_{d S p}$ and $d u_{d S d}$ are the expected pull-out and debonding displacement. The integral interfacial displacement between fibers and matrix can be written as

$$
d u_{d S}=d u_{d S p}+d u_{d S d}=L_{f}\left(N_{d s}-1\right)\left(\frac{1}{4}+\frac{\sigma_{f}}{2 E}\right)
$$

The equivalent integral displacement between fibers and matrix can be written as

$$
u_{e}=L_{f}\left(N_{d s}-1\right)\left(\frac{1}{4}+\frac{\sigma_{f}}{2 E}\right)=L_{f}\left(\frac{4 V_{f}}{9 \pi \phi^{2}}-1\right)\left(\frac{1}{4}+\frac{\sigma_{f}}{2 E}\right)
$$

Shear ca pacity component $V_{u f}$ resulted by fibers, can be solved as

$$
V_{u f}=\frac{W_{f}}{u_{e}}=\gamma \frac{\pi V_{f} d_{f} A_{c} D_{f}\left(4 E \tau_{f m}+D_{f}^{2} \sigma_{f}^{2}\right)}{6 \sin \beta \cdot\left(E+2 \sigma_{f}\right)\left(4 V_{f} L_{f}^{2}-9 \pi D_{f}^{2}\right)}
$$

\subsubsection{USFL of UHPFRC reinforced girder}

From Eqs.(12) and (31), the upper bound solution of UHPFRC beam USFL can be obtained as

$$
\begin{aligned}
V_{u} & =V_{u c}+V_{u f} \\
& =\gamma\left[\frac{1}{2} f_{c}^{*}\left(\frac{1-\cos \beta}{\sin \beta}\right) A_{c}+\frac{\pi V_{f} d_{f} A_{c} D_{f}\left(4 E \tau_{f m}+D_{f}^{2} \sigma_{f}^{2}\right)}{6 \sin \beta \cdot\left(E+2 \sigma_{f}\right)\left(4 V_{f} L_{f}^{2}-9 \pi D_{f}^{2}\right)}\right]
\end{aligned}
$$

\subsection{Cracking load $V_{c r}$ (low bound solution)}

First cracking load $V_{c r}$ for UHPFRC I-girder was found by measuring the moment of the upper tip of the crack in Fig. 10. Diagonal crack is initiated once the first principal stress $\sigma_{1}$ of yield line exceeds the tensile strength of concrete $f_{t}$, and the crack is perpendicular to the direction of $\sigma_{1}$. In the shear/bending area, the direction of $\sigma_{1}$ is a variable due to the combination of shear stress and normal stress, and the crack is curved. A fully developed diagonal crack is illustrated in Fig. 10.

In the case of a critical diagonal crack, the crack is supposed 


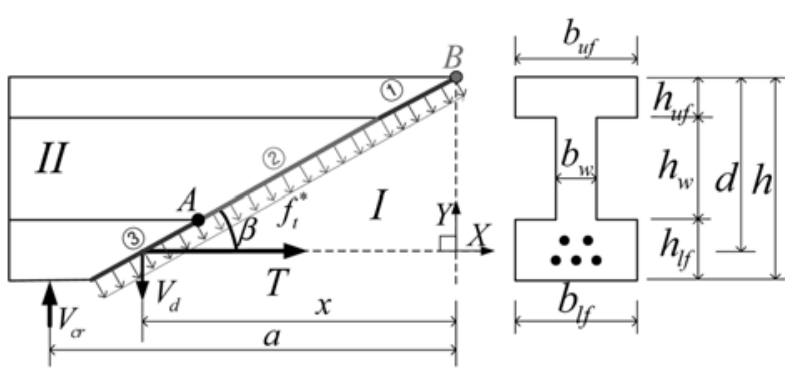

Fig. 10 Critical condition of I-girder.

to be fully developed. Thus a fully plastic equivalent stress distribution may be assumed, i.e. the tensile stress along the path of crack, perpendicular to the crack, is distributed evenly with the value of $f_{t}^{*}$ shown in Fig. 10. This assumption is similar to that of a flexural crack. At ultimate state, the depth of the compressive zone becomes very small. Neglecting this zone, the upper tip of the diagonal crack is assumed to be at point $\boldsymbol{B}$ of the top surface as shown in Fig. 10. The direction of the tensile stress is perpendicular to the crack path. Therefore, the internal moment along the original crack with respect to point $\boldsymbol{B}$ is the same as that along the straight line $\boldsymbol{A B}$. Here, $V_{d}$ is dowel action of longitudinal reinforcing bars. $T$ is equivalent tensile force of reinforcement steel in bottom flange. Aggregate interlock action has been ignored for fine aggregate condition. Three segments (1), (2) and (3), which are divided for moment analysis of distribution tensile stress, can be seen from Fig. 10. Parameter $d$ is effective height.

\subsubsection{Equilibrium analysis}

$$
\begin{gathered}
\sum F_{X}=0 \quad T+f_{t}^{*}\left[h_{u f} b_{u f}+h_{w} b_{w}+h_{l f} b_{l f}\right]=0 \\
\begin{aligned}
\sum F_{Y}=0 & V_{c r}-V_{d}-f_{t}^{*}\left(h_{u f} b_{u f}+h_{w} b_{w}+h_{l f} b_{l f}\right) \cos \beta / \sin \beta \\
& =0, \quad V_{c r}-V_{d}-f_{t}^{*} A_{c} \cot \beta=0
\end{aligned} \\
\sum M_{B}=0 \quad-V_{c r} \cdot a+T \cdot d+V_{d} \cdot x+f_{t}^{*} \frac{\Phi_{1}}{\sin ^{2} \beta}=0
\end{gathered}
$$

where $T$ is the reinforcement steel tensile force and $T=f_{y} A_{s} \cdot f_{y}$ is the yield stress of steel bar. $V_{d}$ is the dowel action of longitudinal steel bar. $A_{c}$ is the general cross section area of the girder. $\Phi_{1}$ is a geometrical constant of the girder cross section and

$$
\begin{aligned}
\Phi_{1}= & \left(h_{u f}^{2} b_{u f}+h_{w}^{2} b_{w}+h_{l f}^{2} b_{l f}+2 h_{w} h_{u f} b_{w}+2 h_{l f} b_{l f} h_{u f}\right. \\
& \left.+2 h_{l f} b_{l f} h_{w}\right) / 2
\end{aligned}
$$

\subsubsection{Cracking load $\boldsymbol{V}_{\boldsymbol{c}}$}

By substituting $V_{d}$, which can be solved from Eq. (33), into Eq. (34), $V_{c r}$ can be obtained as

$$
V_{c r}=\frac{T \cdot d+f_{t}^{*} \Phi_{1} \sec \beta-f_{t}^{*} A_{c} \cot \beta}{a-x}
$$

\subsection{Solution of $x$ and shear loading capacity}

The intersection of the two bounds $V_{u}$ and $V_{c r}$, which can be solved by iteration method, determines both the position of the limit yield line and the shear load carrying capacity.

\section{Numerical calculations and comparative analysis}

Eight reinforced UHPFRC I-girders with two types section and three kinds of shear span ratio were cast and tested. The two bounds were calculated using the model constituted in this paper. The numerical predictions based on two bounds theory are shown in Fig. 11. Theoretical and test results of FDCL and USFL are listed in Table 5.

Proposed FDCL equation had a good agreement with the test results as shown in Fig. 12. It is also noted that FDCL is $50 \% \sim 85 \%$ of USFL, which implies that FDCL has a key significance for UHPFRC reinforced girder. The two limits division is necessary since the big gap was in between FDCL and USFL. Thus, a strength reduction factor 0.8 is proposed here for safety proposed.

Predictions based on conventional formula are also given in the figure. As can be seen, the formula underestimate the shear strength of UHPFRC reinforced girder. Compared with the conventional contribution, the two bounds model proposed gets a correct dimension and more coincides with the corresponding design code of normal concrete. The proposed FDCL formula predictions agree with the corresponding test results well.

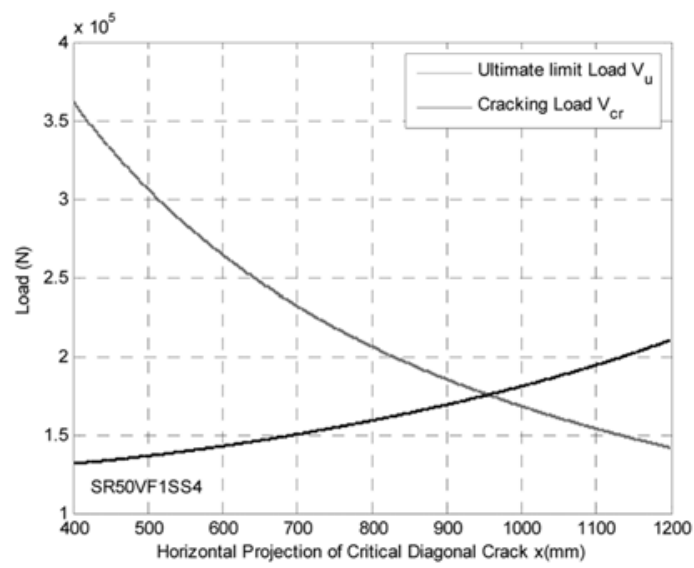

Fig. 11 Variation of the two bounds with crack projection length $x$ (continued). 

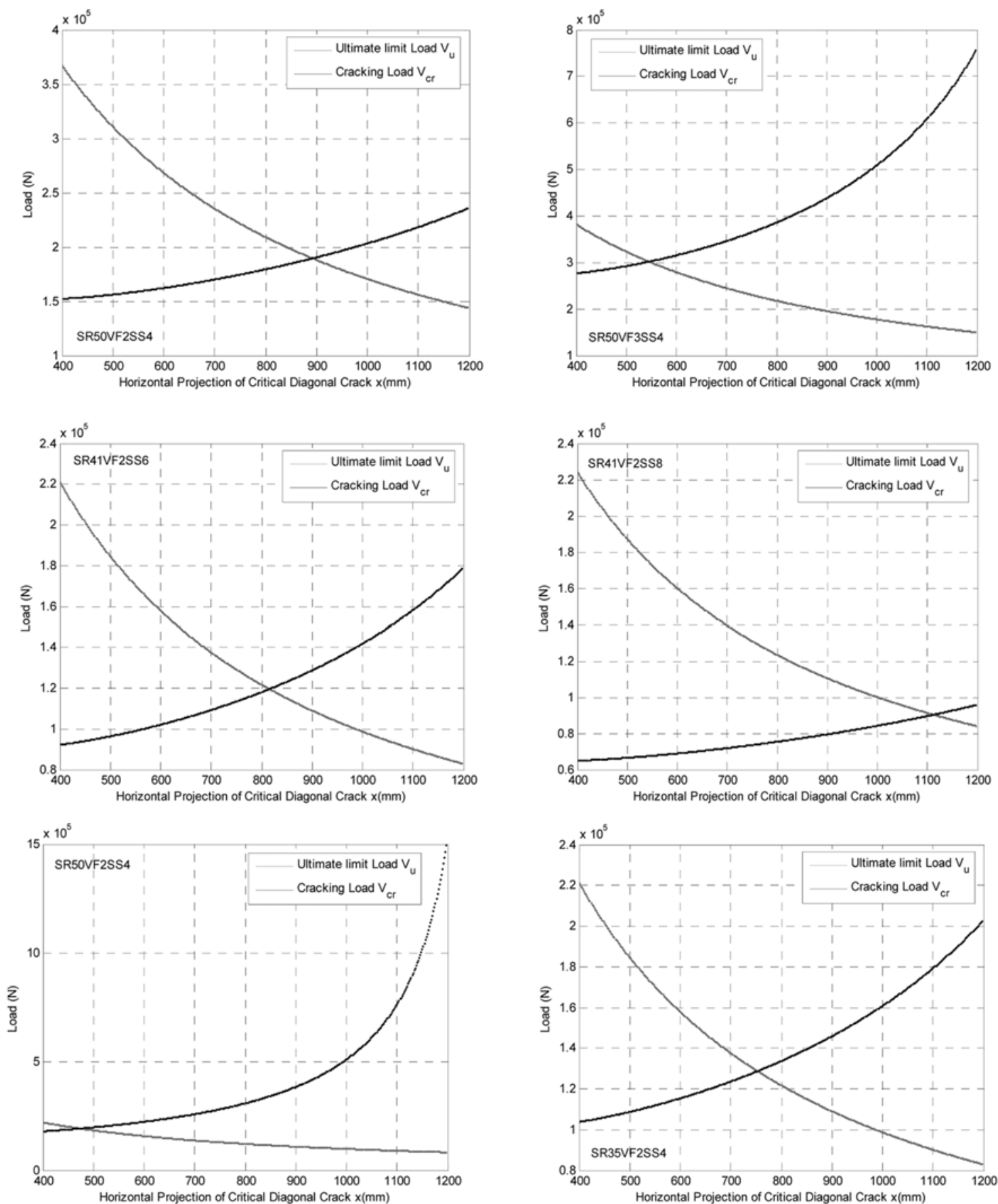

Fig. 11 Variation of the two bounds with crack projection length $x$.

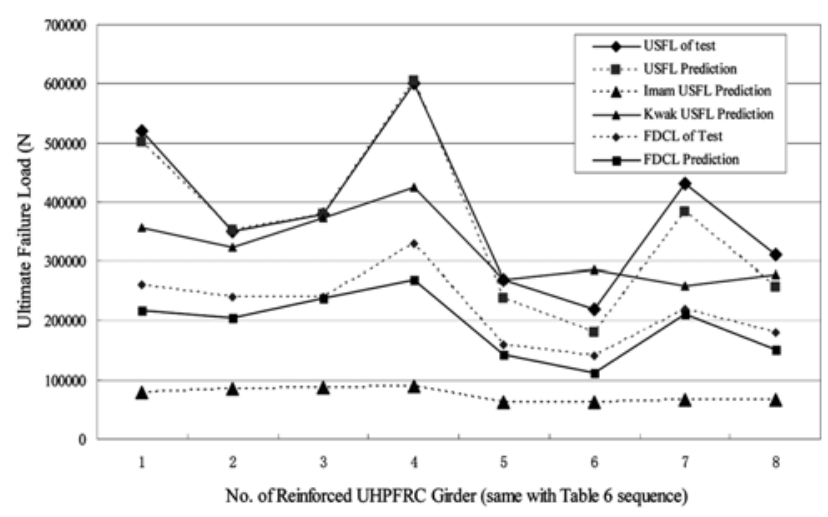

Fig. 12 Comparison of the numerical prediction with test results and others' results.

\section{Conclusions}

Based on theoretical and experimental investigations, the following conclusions are drawn:

1) Research results showed that the first cracking status division is necessary for UHPFRC reinforced girder as the ultimate limit status. From the gap between FDCL and USFL, it indicates that the division is reasonable for UHPFRC reinforced girder. Although the first cracking status is not a structural failure status, it can be a safety design or evaluation limit.

2) Results indicate that the proposed fiber reinforcing model based on uniform distribution assumptions which are the function of fiber physical and geometrical parameters is of key significance. The contributions of pull-out and debonded work can be 
predicted based on micro-mechanics by this model. This model can be a reference for the micro-mechanics mechanism analysis of normal strength FRC.

3) Experimental results on the ultimate shear strength also confirmed that the proposed FDCL and USFL based on the two bounds theory can be references for the first cracking status and the ultimate failure status analysis of UHPFRC reinforced girder, respectively. In addition, the proposed USFL can be used as a numerical analysis reference based on concrete plasticity theory in the future.

4) Conventional formula for normal and high strength FRC are not appropriate to USFL prediction of UHPFRC reinforced girder not only because of far less than USFL of test results but also the lacking of correct mechanics dimensions.

\section{Acknowledgements}

This paper was one part of the research project "Development and Application of High Performance and Multi-Function Concrete" which has now been accomplished. The authors wish to express their gratitude and sincere appreciation to the financial support of "Center of Concrete Corea, Korea."

\section{References}

1. Cavill, B. and Chirgwin, G., "The Worlds First Ductal Road Bridge Sherpherds Gully Creek Bridge," $21^{\text {st }}$ Biennial Conference of the Concrete Institute of Australia, Brisbane, 2003.

2. Okuma, H., "The First Highway Bridge Applying Ultra High Strength Fiber Reinforced Concrete In Japan," $7^{\text {th }}$ International Conference on Short and Medium Span Bridge, Montreal, Canada, 2006.

3. Graybeal, B., Hartamann, J., and Perry, V., "Ultra High Performance Concrete for Highway Bridge," FIB Symposium, Avignon-26-28, April 2004.

4. Sorelli, L., Davila, R., Ulm, F. J., Perry, V., and Seibert, P.,
"Risk Analysis of Early-Age Cracking in UHPC Structures," Proceedings of the Second International Symposium on Ultra High Performance Concrete, Kassel, Germany, March 5 7, 2008, pp. 331 338.

5. Nielsen, M. P., Limit Analysis and Concrete Plasticity, Prentice Hall, Inc. Englewood Cliffs, New jersey, 1984, pp. $1 \sim 28,205 \sim 235$.

6. Ashour, A. F., "Upper Bound Analysis for Reinforced Concrete Deep Beams with Fixed End Supports," ACI Struct. Journal, Vol. 96, No. 2, 1999, pp. 167 173.

7. Imam, M., Vandewalle, L., Mortelmans, F., and Van Gemert, D., "Shear Domain of Fibre-Reinforced High Strength Concrete Beams," Journal of Engineering Structures, Vol. 19, No. 9, 1997, pp. 738 747.

8. Kwak, Y. K., Eberhard, M. O., Kim, W. S., and Kim, J., "Shear Strength of Steel Fiber-Reinforced Concrete Beams without Stirrups," ACI Structural Journal, Vol. 99, No. 4, 2002, pp. $530 \sim 538$.

9. Hoang, L. C., Shear Strength of Non-Shear Reinforced Concrete Elements, Part 2-T-Beams, Report No. 29, Technical University of Denmark, Department of Structural Engineering and Materials, Lyngby, 1997, $35 \mathrm{pp}$.

10. Hoang, L. C., Shear Strength of Non Shear Reinforced Concrete Elements. Part 1-Statically Indeterminate Beams, Technical University of Denmark, Department of Structural Engineering and Materials, Report R No. 16, Lyngby, 1997.

11. Zhang, J. P., Strength of Cracked Concrete. Part I-Shear Strength of Conventional Reinforced Concrete Beams, Deep Beams, Corbels and Prestressed Reinforced Concrete Beams without Shear Reinforcement, Technical University of Denmark, Department of Structural Engineering, Report R No. 311, Lyngby, 1994.

12. Sharma, A. K., "Shear Strength of Steel Fiber Reinforced Concrete Beams," ACI Journal, Vol. 83, No. 1, 1986, pp. 624 628.

13. Beaudoin, J. J., Handbook of Fiber-Reinforced Concrete (Principles, Properties, Developments and Applications), Noyes Publications, New Jersey, USA, 1990, 22 pp. 